\title{
The Role of Peer Facilitator in Enhancing English Language Proficiency in a Simulated Environment
}

\author{
Nur Salina Ismail ${ }^{1}$, Engku Suhaimi Engku Atek ${ }^{1}$, Mohd Nazri Latiff Azmi ${ }^{1} \&$ Mahani Mohamad $^{1}$ \\ ${ }^{1}$ Faculty of Languages and Communication, Universiti Sultan Zainal Abidin, Malaysia \\ Correspondence: Engku Suhaimi Engku Atek, Faculty of Languages and Communication, Universiti Sultan \\ Zainal Abidin, Malaysia. E-mail: esuhaimi@unisza.edu.my
}

Received: October 20, 2014 Accepted: November 24, 2014 Online Published: January 20, 2015

doi:10.5539/elt.v8n2p78 URL: http://dx.doi.org/10.5539/elt.v8n2p78

\begin{abstract}
For many learners, language class can be anxiety-provoking than other courses. Mostly, university students are seen to have language anxiety especially in their second language learning. They tend to be nervous when using English language in the formal situation like in classroom. English Outdoor Programme (EOP) in 2011 as part of informal setting was carried out by Universiti Sultan Zainal Abidin (UniSZA) in an effort to improve the standard of English of its students. The study aims to explore the role of peer facilitators in assisting the students learning English during the EOP from the view of participants and the peer facilitators themselves. This research applies mixed method approachusing questionnaire and interview with both participants and peers involved in this programme. Data obtained from the questionnaire was analysed using SPSS and data from interview was analysed using thematic coding to answer the research objectives given. A significant finding is the positive role the peer facilitators had in the participants' language learning process; not only for the participants but also the peer facilitators themselves.
\end{abstract}

Keywords: peer facilitators, simulated environment

\section{Introduction}

Malaysian university students generally have limited proficiency in the English language causing problems in their academic life (Mustafa, 2006). Undergraduate students are found to not having note-taking skills and this creates problem to them when listening to lectures or discussions. Additionally, learners at tertiary education are found to have limited vocabulary knowledge and are weak at understanding long sentences or sentences with difficult words (Muhammad, 2007; Radha, 2007; Hasan, 2008). Noor Hashimah Abdul Aziz (2007), in her study on language anxiety among English language learners at tertiary education, reported that the majority of learners were very nervous when speaking in English and that they face great difficulty to express themselves in English. In an effort to partly address the lack of English proficiency among students, Universiti Sultan Zainal Abidin (UniSZA) introduced a special English programme in 2011 for undergraduates with limited English proficiency. Known as the English Enhancement Programme (EEP), it was an out of class English learning activity programme carried out in the first quarter of 2011 to raise the standard of English of UniSZA students. Within this programme, selected students were camped in a programme known as English Outdoor Camp (EOP) to learn English through fun language activities. The uniqueness of this programme is that the activities were well designed to suit students' level of proficiency and were carried out solely by facilitators who were also students of the same age.

Hence, this study intends to investigate the role of peer facilitators in assisting the participants learning English during the English Outdoor Camp (EOP).

\section{Language Learning Environment}

Learning is associated with skill development, practical knowledge, andaction-the result or residue of experiential learning is the long term memory associated with it. Researchers and educators have been studying ways to enable learners to use English freely, effectively, and as far as possible accurately, in realistic communication. This has become not only the major goal of all English language teaching, but also the students' main concern when they make their efforts to study English (Jing, 2006). In the context of this study, language learning experience refers to the exposure to the target language involving formal or informal language learning 
activities, situations or environments. This may include classroom learning, outdoor learning and any language activity meant to promote and enhance the language ability of the learner. In Malaysia, students spend between 11 and 13 years (6 years in primary school and between 5 and 7 years in secondary school) learning English, but when they enter universities, a large majority of them are still not able to master the language upon completing secondary school (Govindasamy \& Latiff Azmi, 2010). There are various factors that could have contributed to these failures; learners' learning methods, motivation, perceptions, teachers' teaching methods and/or approach, syllabus and lesson plan, among others. Therefore, it is imperative to understand learners' views and experiences in learning a second language in order to identify the difficulties and impediments that they encounter in the classrooms.

In the past, there were few studies of classroom anxiety of Asian learners; the number of such studies has been growing. Osboe, Fujmura, and Hirschel (2007) stated that there was a positive correlation between low anxiety and utilization of small group activities in oral English classes. Language learning itself is a lifelong task, and language-learning strategies are important skills for students' self-directed language learning. It appears that successful language students have the ability to orchestrate and combine particular types of language learning strategies in effective ways, according to their own learning needs (Rosniah, 2006). Thus, to facilitate students' language learning and to promote learner autonomy, language-learning strategies are a key point for instructors to which one must pay attention. Improving the vocabulary and comprehension of students are ESL teaching strategies that are usually approached with language proficiency improvements, critical thinking, and study skills. However, such ESL programs are still misunderstood and are not yet proven effective (Chang, 2000). Much research has focused on second language development and academic success. However, the debate continues on which instructional approach is the most effective with second language learners.

In short, these inter-related factors are due to many ESL students getting low or failing grades in completing their English proficiency test as a core subject for different purposes e.g. foreign admission, job interview, university admission etc., because they performed poorly especially on the listening comprehension and oral interview parts of the tests.

Teaching a language is challenging but it is more testing when the surrounding is not supportive of the target language. The success of the method relies on a combination of modules, teachers and the suitability of the environment. "In second language learning, students find difficulties to utilise the language skills outside of language classrooms as there are fewer opportunities to do so due to poor language environment, however, creative teachers are able to create English stimulated environment especially at special places in school compound" (Maesin, 2009). Chang and Shu (2000) argue that there is a positive relationship between the learning environment and student motivation, stating that a good learning environment helps improve the learning outcomes, and inspires and boosts the learning spirit. A review paper by Long and Porter (1985) that analysed findings across studies that compared interaction among learners outside classroom situations with that among learners in teacher-fronted lesson, as quoted by Pica, Lincoln-Porter, Paninosk, and Linnell (1996) revealed that learners working together in groups in an informal setting were found to display greater motivation, more initiative and less anxiety regarding their learning. This is further evidence that interaction in outdoor activities facilitates and promotes second language learning.

Hence, the EEP was introduced to cater for students who were considered to have low proficiency of the English language to enable them to gain the confidence to use the language. The EEP was divided into two components: Indoor and Outdoor programmes. The Indoor programme was carried out for a period of two months during the semester, with activities conducted every alternate weekend on-campus. The activities carried out integrated the four language skills of listening, speaking, reading and writing. An important feature of the Indoor programme was the experiential learning as the activities incorporated the five major modes propagated by Gibbons and Hopkin (1980). These are receptive, analytical, productive, development and psychological modes. Another key feature of the programme is the creative, supportive and expressive environment it would create. Everyone involved in the programme would contribute to the creation and maintenance of such environment that would encourage participation

The English Outdoor Programme (EOP), the second component of the EEP, was a one-off programme carried out off-campus over a period of three days and two nights at a nearby resort. While integrating all the four language skills, the main focus of EOP had always been on the advancement of oral skills. All the participants were assisted by the peer facilitators who were responsible for running the EOP as well as assisting, guiding and facilitating the participants in their activities.

There were a total of seven language activities carried out during this outdoor programme. They were Treasure 
Hunt, Campfire Story, Holiday Package, Tongue Twisters, Show and Tell Me—Origami, Hot Seat and Who am I?

Both the EEP and EOP are considered to be a type of learning programme carried out in a simulated environment. Merriam-Webster (2011) dictionary defines simulated as "artificial" or "made to look authentic". In the context of this study, a simulated environment is defined as a non-authentic, non-English speaking environment that mimics an authentic English speaking environment through the adoption of the principles of immersion in its language learning process. This enables learners to immerse themselves in the target language in an informal, outdoor setting that is supportive and conducive to learning that language through the highly intensive "English-only" immersion programme. The EOP is further characterised as a type of activity-based learning that is supported by group activities that required participants to actively engage themselves in the use of the English language.

The uniqueness of this programme is that it was run by the peers themselves as the facilitators. In this study, peers refer to fellow students who act as facilitators for the programme. They are university undergraduate students who were specifically trained for the EOP. Peers as reflected in this research refers to behaviorist theories by Maslow (1954) whereby relationships between people affect learning only as much as people reinforce each other (or not) in the academic arena. For example, if the peer group encourages education and learning, then the individual student within that group will value learning, because the individual is reinforced, or rewarded, for behavior that indicates that learning is valued.

Topping and Ehly (1998) define peer-assisted learning as "the acquisition of knowledge and skill through active helping and supporting among status equals or matched companions". Reciprocal peer-assisted learning as "employs same-age student pairs of comparable ability with the primary objective of keeping both peer student and peer teacher engaged in constructive academic activity" (Fantuzzo \& Ginsburg-Block, 1998, p. 121). Researches have proven that a learning process using peers rather than teachers is more effective. The best method to stimulate learning is interaction with peers (Topping, 1996) because students assisted by peers are more active and engaged in their learning. Fitz-Gibbon and Reay (1982), in their study on the attitudes of children to the study of French in a British school, concluded that peer tutoring increased their motivation to learn the language. Positive behaviours and reactions of the subjects support the view of Seng (2006) who acknowledged that students were able to learn better when a classmate explains something to them due to less formality and boundary that the former feels when with the teachers.

According to Ohta (2001), the benefits of peer as in peer interaction has outweighed the negative effects as through scaffolding, learners build "bridges to proficiency" (p. 125). This scaffolding, together with the internalization of the language occurring in social interaction, supports L2 development. With this peer facilitating, students are becoming more on themselves rather than on teacher as promoted by Gardner and Miller (1997). In other aspects, it also promotes in encouraging learner autonomy in the language classroom (Allwright, 1988). Hence, it can be summarized that in the context of peer facilitating, active involvement of students in developing learning materials and activities is seen as contributing to a student-centred approach and to learner autonomy, as well as being conducive to students' learning (Thompson, 1992).

Peer support is becoming a popular supplement to the traditional methods in second language learning (Deegan, 2006). Studies have shown that employing peer support system in language learning creates a more positive environment.

The research aims to study the roles of peer facilitators involved in this programme. This study investigates the perceptions of both the participants and peer facilitators in learning English in this simulated environment of the EOP and the roles the peer facilitators had on the participants in assisting them to learn English. Specifically, the research questions of the study are: 1) From the EOP participants' perception, how did the peer facilitators play their role in assisting them to learn English? 2) From the perception of the peer facilitators, how did they assist the EOP participants to acquire their English language?

\section{Methodology}

This research applies a mixed method approach. It employs a mixed method convergent parallel design which consists of two distinct phases: quantitative followed by qualitative (Cresswell, Plano Clark et al., 2003). The type of research design used to conduct the research was a case study (Idris, 2010). Case study researches about one particular unit or sample in a certain time only. This research is used to observe about a specific phenomenon and in the last stage the result is used to guess about a bigger population unit on the same phenomenon. This research uses a case study type because it focuses on all participants who underwent English outdoor camp only and it was conducted within a specific time frame of 3 days. As the research also uses all 
samples in the population, the case study type was deemeda suitable research design to control bias factors that could refrain the result of the research from becoming invalid. In this design, the researchers first collected and analysed the quantitative (numeric) data collected from the participants of the camp. Later, the qualitative (interview) data was collected and analysed from both the participants and facilitators to answer the quantitative results obtained in the first phase. The second, qualitative phase was built on the first, quantitative phase which focused on the interview that involved both the participants and facilitators. Subsequently the two phases were connected in the intermediate stage in the study. The rationale for this approach is that the quantitative data and their subsequent analysis provide a general understanding of the research problem which is to investigate the ESL teaching and learning using an outdoor simulated environment. The qualitative data and statistical results were then refined and explained by exploring participants' and peers' views in more depth (Cresswell, 2003; Rossman \& Wilson, 1985; Tashakkori \& Teddlie, 1998).

The population of the studies is comprised of all the participants and peer facilitators of the EOP. There were 68 mixed-gender students of various first degree and diploma programmesfrom Universiti Sultan ZainalAbidin, Malaysia who participated in the programme. In addition, there were 19 students of the Bachelor of English programme from the same university who were selected as peer facilitators for the programme.

There were two categories of respondents for the study: EOP participants and peer facilitators. In the first category, the subjects of this study were all 68 EOP participants in the age range of 18-21 years old from various educational background and courses. They were considered students with limited English proficiency based on their previous English grade in the SPM examination. The SPM, or the Malaysian Certificate of Education examination, is a compulsory national higher education entrance examination for all Malaysian school students taken at the end of Form 5 after undergoing five years of secondary school education. All of these respondents were enrolled in the first semester of the academic session. The breakdown of the respondents is presented in Table 1 below:

Table 1. Demographic profile of respondents

\begin{tabular}{lll}
\hline Category & $\mathrm{N}$ & Percentage \\
\hline Gender & & \\
\hline Female & 53 & 77.9 \\
Male & 15 & 22.1 \\
\hline Level of studies & & \\
\hline Degree & 46 & 67.7 \\
Diploma & 22 & 32.3 \\
\hline
\end{tabular}

The majority of the respondents were female students. Out of 68 respondents, 15 were male and 53 were female students. Almost four-fifths $(77.9 \%)$ of the respondents were female students. As for their level of studies, there were $46(67.7 \%)$ degree and $22(32.3 \%)$ diploma students respectively.

The second category of respondents, the peer facilitators, is comprised of 19 students from the Bachelor of English programme. These were students in 2nd and 3rd year of degree programme who were selected based on their excellent command of the English language. Upon appointment as facilitators, they underwent a course designed to train them as the EOP facilitators

Since this research is a mixed method approach, two different instruments were used to collect data: questionnaire and interview. A primary survey using a detailed set of questionnaire was administered to the participants. The questionnaire consisted of: 1) demographic data on gender and level of study and 2) role of facilitators (7 items). In order to gain participants' perception on the role of facilitators, the respondents were asked to rate the statement items under a 4-point scale ranging from strongly disagree to strongly agree.

The second instrument was a structured interview. Two separate interviews were conducted. The first interview involved 16 EOP participants, randomly chosen, representing approximately $25 \%$ of the respondents. The interview questions mainly sought their opinions regarding the role of facilitators in assisting them to learn English. The second interview involved all 19 peer facilitators. They were asked questions on their role as facilitators and how they helped improve the participants' language skills, their opinion on activities and whether they perceived learning English outdoor or in the classroom would be more effective. 
The present study investigated the participants' and peer facilitators' perceptions of the role of facilitators had on the participants in assisting them to learn English. Data collection contained questionnaire and interviews. The data was collected within a week of the completion of the EOP. This was done mainly for clarity and recall purposes on the part of the respondents in order not to jeopardise the quality of data collected. For quantitative data, the participants were administered the questionnaire simultaneously on the last day of the EOP. It took them approximately 30 minutes to complete the questionnaire. For qualitative data, one-third of the participants were selected randomly to be interviewed to get an in-depth explanation of their participation during the EOP. All peer facilitators of the EOP were interviewed within seven days of the completion the programme. This procedure was administered in order to get personal views on their roles in assisting the participants to learn English. Each interview was conducted in the friendly atmosphere of the researcher's office and lasted between 20 and 25 minutes.

In this study, data were analysed quantitatively and qualitatively. The questionnaire was analysed using SPSS version 16.0 for mean by using descriptive statistics. Descriptive statistics analysis was used to obtain result from research objective 1; participants' perceptions of role of peer facilitators inassisting the students in acquiring their English language. All findings were tabulated using mean. Meanwhile analysis for interview was done using the thematic coding for research objective 2 .

For the questionnaire, the mean score indicator shown in Table 2 is used to interpret and analyse the participants'perceptions.

Table 2. Mean score indicator on perception

\begin{tabular}{ll}
\hline Mean Score & Perception Description \\
\hline $1.00-1.75$ & Very Negative \\
$1.76-2.50$ & Negative \\
$2.51-3.25$ & Positive \\
$3.26-4.00$ & Very Positive \\
\hline
\end{tabular}

\section{Results}

1) From the EOP participants' perception, how did the peer facilitators play their role in assisting them to learn English?

To answer this research question, the researchers used the item extracted from the questionnaire. Table 3 shows the respondents' perceptions of the role of peer facilitators. The results suggest that respondents rated their facilitators very positively in all but Item $5(\mathrm{~m}=3.24)$, which was only rated as positive. The respondents perceived Item $1(\mathrm{~m}=3.44)$ most positively.

Table 3. Perception on peer facilitators

\begin{tabular}{llll}
\hline & $\mathrm{N}$ & Mean & SD \\
\hline 1. Facilitators were supportive. & 68 & 3.44 & .70 \\
2. Facilitators encouraged participation in all activities. & 68 & 3.32 & .68 \\
3. Facilitators motivated participants to use English during the EOP. & 68 & 3.28 & .62 \\
4. Facilitators were well-trained to conduct activities. & 68 & 3.26 & .66 \\
5. Facilitators' command of English was understandable. & 68 & 3.24 & .63 \\
6. Facilitators were friendly. & 68 & 3.43 & .76 \\
7. Overall, facilitators were effective in their role to assist learning. & 68 & 3.32 & .68 \\
Overall & 68 & 3.33 & .50 \\
\hline
\end{tabular}

To further support how peer facilitators assisted the students in acquiring their English language from the perspective of participants, results from interview with participants were used. From the interview conducted on 
the participants, the data revealed that all the respondents enjoyed learning English in this simulated environment because it gave them a different experience to learning in the classroom. On top of that, according to them, they felt comfortable to use the language with the peer facilitators. Furthermore, the participants were of the view that outdoor learning is more practical as there were language activities conducted that allowed them to enjoy using English freely especially with the other participants and also withthe peer facilitators. Other than that, the data revealed that most participants regarded facilitators as someone who is helpful, approachable, friendly and supportive. They assisted participants in completing the task assigned and at the same time correcting participants' mistakes in sentences and vocabulary. Peer facilitators helped them a lot in correcting their pronunciation. Besides, according to the participants, the facilitators enforced and ensured that English was consistently used throughout the camp. The facilitators' helped them in raising their confidence to use English language.

2) From the perception of the peer facilitators, how did they play their role in assisting the EOP participants to learn English?

Based on the interviews with the peer facilitators, the researchers found that the majority of the peer facilitators understood their roles to not only help the participants improve their English language proficiency but also enhanced the participants' language skills, in particular their spoken language. This is based on their responses from the qualitative data which show the peer facilitator's role in assisting the participants such as PF2 to motivate and support, PF5 to facilitate, PF6 to give moral support, PF7 to create speaking environment, PF9 to trigger them to speak, PF10 to help them to feel comfortable. From another aspect, the peer facilitators themselves gained positive benefits by being involved in the programme as mentioned by PF1, PF3, PF9, PF10 to have a partner to speak English and improve pronunciation, PF3, PF12 to encourage to speak in English, PF8 to build self-confidence and PF15 to develop own language skill. From another point of view, the roles of peer facilitators which were considered less formal compared to the participant's language teachers in the classroom has also inspired the participants to learn English (PF18), to become a good listener (PF11), to correct mistakes (PF15, PF10, PF17) and also to give guidance and motivation (PF16). From another point of view, almost all of the participants agreed that the peer facilitators were approachable, supportive, helpful and friendly. More importantly, the participants were in total agreement that the peer facilitators successfully carried out both positions: facilitators and peers, and this is one of the contributing factors for the success of the programme.

\section{Discussion}

Based on the findings discussed earlier, in terms of the students' perceptions on the simulated peer facilitator, this study clearly indicates that the participants have very positive attitudes towards their facilitators. This implies that the approach taken by UniSZA to involve students with limited English proficiency to undergo this programme has been well-received. The students' very positive experience of the simulated learning environment is further enhanced by the role the facilitators played during the programme. The participants perceived that peer facilitators were effective in their role in assisting the learning of the language. This is because the participants claim that they were comfortable to learn English language among their own counterparts in less formal setting. This evidence is fully in line with (Chang \& Shu, 2000; Seng, 2006) that good and less formal learning environment plays a role in the success of learning. Again, the choice of students as facilitators may have been a factor. Findings from this study suggest that the peer facilitators have played their role effectively to motivate, assist and guide the students. Peer facilitators also were found to be very supportive, cooperative and friendly towards the participants. Meanwhile findings from the interview gathered from the participants, a role as facilitator was clearly displayed by the peer facilitators especially in assisting English language learning especially in correcting their grammar and also pronunciation. Thus it can be concluded that participants were confidently communicating in English with their own counterparts as supported by Pica, Lincoln-Porter, Paninos and Linnell (1996) that such learning experience that takes place will be less formal and lower the anxiety to communicate.

Based on the second research question addressed, it can be clearly proven from the data gathered from the peer facilitators that they were conscious of their role as facilitators in assisting the English language learning. Evidently, having peers acting as facilitators to carry out their roles in ensuring English language learning in the simulated learning environmentis considered a big achievement. They were fully aware that their roles not only helped improve the English proficiency of the participants but also their intrinsic motivation. The peers also managed to build up their soft skills and self-esteem due to the recognition and respect given by the participants. Being approachable facilitators with less formality attached compared to classroom teaching and being good listeners have created a meaningful language simulated environment. All these factors were in line with Nambiar (2007) who stressed on less formality and flexible approaches in language teaching at tertiary level. The findings 
are in line with the study done by Paninos and Linnel (1996) which stresses that an informal setting in learning would create greater motivating factors and benefit both parties - teacher and learner. This language intrinsic motivation shows that as peers, the facilitators managed to implement their soft skills (leadership skills) in making sure that the participants gain world knowledge through learning English.

\section{Conclusion}

Based on the findings, it is proven that method of language teaching and learning helps students especially those who have low proficiency level in the language. The method mentioned covers the environment and the facilitators involved in the learning process. Thus, this study has given a vast contribution in promoting outdoor or simulated environment in language learning. The simulated learning promotes active learning through direct personal experience and offers excitement, fun and adventure within the framework of a planned syllabus. Methods used include skills-focused learning, problem solving, team building and self-reliant journeys and activities. The role of facilitators also gives a significant impact in ensuring language is learned effectively with low level of anxiety. Overall, language challenging experience outdoors impacts powerfully upon a participant's intellectual, physical, spiritual, social and moral development.

This study provides clear evidence that the use of the outdoors makes a major contribution to effective language learning especially in communicating the language. This study has shown that participants felt comfortable in using the language especially when communicating with both their colleagues and the peer facilitators. Hence, there is also a great deal of intrinsic enjoyment and satisfaction to be experienced from participation in outdoor activities. Eventually, building self-confidence and self-esteem is fundamental to any language learner's development.

From another point of view, the study proves that participation in exciting and enjoyable outdoor activities with peers as facilitators reinforces a positive attitude to education and contributes significantly to the general ethos of an institution or youth group. Direct experience outdoors stimulates and reinforces learning across many areas of the curriculum, and the use of the outdoors encourages young learners to take greater responsibility for their own learning.

The study has given a meaningful guide in encouraging rich opportunities for personal and social development through carefully structured group work in challenging situations. Trust, care, tolerance and the willingness to give and accept support are all encouraged and anti-social behaviour is challenged. Opportunities are presented to exhibit and develop effective inter-personal behaviour and to work co-operatively and effectively in teams.

\section{References}

Allwright, D. (1988). Autonomy and Individualization in whole-class instruction. In A. Brookes, \& P. Grundy (Eds.), Individualization and Autonomy in Language Learning (pp. 35-44). London: Modern English Publications and the British Council.

Aziz, N. H. A. (2007). ESL students' perspectives on language anxiety (Unpublished Ph.D. thesis). Universiti Putra Malaysia: Serdang.

Chang, C. P., \& Shu, M. Z. (2000). The experiment research for English teaching with small class of junior high school. The Ministry of Education, the 2000 Academic year Research Project of Taiwan High School Technician Conference.

Cresswell, J. W., \& Plano Clark, V. L. (2011). Designing and Conducting Mixed Methods Research. Sage Publication: Los Angeles.

Deegan, P. (2006). The Legacy of Peer Support. Retrieved May 30, 2014, from http://www.patdegan.com/blog/ posts/legacy-peer-support

Fantuzzo, J., \& Ginsburg-Block, M. (1998). Reciprocal peer tutoring: Developing and testing effective peer collaborations for elementary school students. In K. Topping, \& S. Ehly (Ed.), Peer-assisted learning (pp. 121-145). Mahwah, NJ, \& London: Lawrence Erlbaum Associates.

Fitz-Gibbon, C. I., \& Rear, D. G. (1982). Peer Tutoring: Brightening up FL Teaching in an Urban Comprehensive School. British Journal of Language Teaching, 20(1), 39-44.

Gardner, D., \& Miller, L. (1997). A Study ofTertiary Level Self-Access Facilities in Hong Kong. Hong Kong: City University of HongKong, Management Committee of Evaluationof the Student Experience Project.

Govindasamy, S., \& Latiff Azmi, M. N. (2010). The Impact of National Language Policy on Second Language Development from Reading Perspective. International Journal of Multidisciplinary Thought, 12, 9-15. 
Hasan, Z. A. (2008). Peer interaction and meaning construction among ESL learners in comprehending texts in 2nd language context (Unpublished Ph.D. thesis). Universiti Putra Malaysia: Serdang.

Idris, N. (2010). Penyelidikan Dalam Pendidikan. McGraw Hill.

Jing, W. U. (2006). Integrating skills for teaching EFL-Activity design for the communicative classroom. Sino-US English Teaching, 3(12).

Long, M., \& Porter, P. A. (1985). Group Work, Inter-language Talk, and Second language Acquisition. TESOL Quarterly, 19(2). http://dx.doi.org/10.2307/3586827

Maesin, A., Mansor, M., Shafie, A. L., \& Nayan, S. (2009). A Study of Collaborative Learning among Malaysian Undergraduates. Asian Social Science, 5(7), 70-76. http://dx.doi.org/10.5539/ass.v5n7p70

Maslow, A. H. (1954). Motivation and personality. New York: Harper. http://dx.doi.org/10.1111/j.1467-6494. 1954.tb01136.x

Muhammad, A. M. (2007). The effectiveness of an academic reading course in facilitating tertiary students' comprehension of academic text (Unpublished Ph.D. thesis). Faculty of Education, Universiti Kebangsaan Malaysia, Bangi.

Mustaffa, R. (2006). The effects of culture on students' learning styles. $3 L$ the Southeast Asian Journal of English Language Studies, 12, 83-94.

Ohta, A. S. (2001). Peer interactive tasks and assisted performance in classroom language learning. In A. S. Ohta (Ed.), Second language acquisition processes in the classroom: Learning Japanese (pp. 77-128). Mahwah, $\mathrm{Nj}$ : Lawrence Erlbaum.

Osboe, S., Fujmura, T., \& Hirschel, R. (2007). Students' confidence and anxiety in L2 speaking activities. Languaging, 10, 32-35.

Pica, T., Lincoln-Porter, F., Paninos, D., \& Linnell, J. (1996). Language learners' interaction: How does it address the input, output, and feedback needs of 12 learners? TESOL Quarterly, 30(1), 59-84. http://dx.doi.org/10.2307/3587607

Radha, M. K. N. (2007). Enhancing academic literacy among tertiary learners: A Malaysian experience. $3 L$ the Southeast Asian Journal of English Language Studies, 13, 77-94.

Seng, H. (2006). Cooperative Learning and Achievement in English Language Acquisition in a Literature Class in a Secondary School (Unpublished Master Dissertation). University Technology Malaysia, Shah Alam.

Thompson, P. S. (1992). Cognitive Styles and the Student as Teacher. French Review, 65(5), 701-707.

Topping, K. (1996). The Effectiveness of Peer Tutoring in Further and Higher Education: A Typology and review of the Literature. Higher Education, 32(3), 321-345. http://dx.doi.org/10.1007/BF00138870

Topping, K., \& Ehly, S. (1998). Peer-assisted learning. Mahwah, NJ, \& London: Lawrence Erlbaum Associates.

\section{Copyrights}

Copyright for this article is retained by the author(s), with first publication rights granted to the journal.

This is an open-access article distributed under the terms and conditions of the Creative Commons Attribution license (http://creativecommons.org/licenses/by/3.0/). 